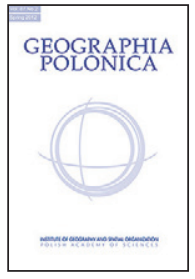

\title{
GEOSPATIAL AND TEMPORAL ANALYSIS OF DROUGHT YEARS IN ZIMBABWE, 1940-1999
}

\author{
Geoffrey Mukwada ${ }^{1}$ Desmond Manatsa ${ }^{2}$ \\ ${ }^{1}$ University of the Free State \\ Department of Geography \\ Private Bag X13, 9866 Phuthaditjhaba: South Africa \\ e-mail address: gmukwada@gmail.com \\ ${ }^{2}$ Bindura University of Science Education \\ Department of Geography \\ Private Bag 1020, Bindura: Zimbabwe
}

\begin{abstract}
The purpose of this research study was to determine the geospatial and temporal characteristics of the drought years in Zimbabwe for the period between 1940 and 1999. Using time series analysis, spatial analysis and the Kruskal-Wallis test, the study established that there has been a gradual increase in the frequency of 'drought years' in the recent past, suggesting that some parts of the country might be experiencing climate change. The study concludes that the nature of government initiated intervention strategies for improving agriculture in arid areas may now have to be considered for adoption in areas normally conceived as moist.
\end{abstract}

\section{Keywords}

agriculture - drought - food security - geospatial analysis - rural livelihoods $\bullet$ time series analysis - Zimbabwe

\section{Introduction}

The increase of climatic variability during the past twenty years has been characterized by disastrous droughts world over (Houghton et al. 2001; Manatsa et al. 2010). Drought is a complex phenomenon that affects more people, worldwide, than any other natural hazard and results in serious economic, social, and environmental impacts, and although drought affects virtually all climatic regimes and has significant consequences in both developed and developing countries, its impacts are especially serious in developing countries where dryland (rainfed) agriculture predominates (Wilhite 2003). Due to limited resources developing countries become vulnerable because they find it difficult to adapt, socially, technologically and economically (Some'e et al. 2012). For instance, in Zimbabwe, where agriculture is largely rainfed (Manatsa et al. 2012), it was estimated that 1.4 million people required food aid during the 2011-2012 agricultural period as a result of drought induced chronic food insecurity (http:// www.fews.net/zimbabwe). In Zimbabwe, more than $60 \%$ of the population depends on rainfed subsistence or semi-subsistence farming for livelihood and is vulnerable to drought (Makaudze \& Miranda 2010).

Though coining a concise definition for drought is not easy, all definitions seem to agree that 
drought is a condition of insufficient moisture caused by a deficit in precipitation over some time period (Hallack-Alegria \& Watkins 2007). In this study we define drought as a meteorological phenomenon characterized by a prolonged and abnormal moisture deficiency (Kim \& Valdes 2002). However, mindful of the fact that the concept 'drought' has been subjected to varied interpretations, in this study we coin the operational term 'drought year' to connote a year in which the total annual rainfall received at a place is less than sixty year average annual rainfall received at that place, the minimum amount required for 'normal' rainfed crop production in Zimbabwe (Manjengwa et al. 2012). Thus, a meteorological station would have experienced a drought year if its total annual rainfall fell below the long-term average of the annual rainfall recorded in the area in which the station is located.

\section{Geographical patterns of rainfall in Zimbabwe}

In Zimbabwe, the amount of rainfall received is distributed according to agro-ecological regions (Fig. 1). The average annual rainfall received in the country is highly variable, spatially, ranging from from $337 \mathrm{~mm}$ in the extreme southern part of the country to $1110 \mathrm{~mm}$ on the Eastern Highlands (Mazvimavi 2008). Like in the rest of the southern African region, rainfall variability occurs at all timescales (Mason \& Jury 1997; Tyson \& Preston-Whyte 2000; Reason \& Rouault 2002), making the country susceptible to severe droughts. As shown in Figure 1, Zimbabwe is divided into five main agro-ecological zones, the more moist agro-ecological regions I, II and III from the relatively more arid ones, termed regions IV and V. In regions I, II and III average annual average rainfall varies from $650 \mathrm{~mm}$ to well over $1000 \mathrm{~mm}$, while in agro-ecological regions $\mathrm{IV}$ and $\mathrm{V}$ it ranges from amounts below $450 \mathrm{~mm}$ to $650 \mathrm{~mm}$ (Vincent \& Thomas 1960). Therefore, technically speaking the $650 \mathrm{~mm}$ isohyet is the divide between the moist and the arid areas in the country. The arid areas are characterized by erratic rainfall and frequent dry spells, rendering crop production completely uncertain. On the other hand crop cultivation is more widely practiced in agro-ecological regions I, II and III. Over 80\% of Zimbabwe's population lives in the communal areas, most of which are located in the drought prone agro-ecological regions III and IV (Fig. 1).
In a typical drought year the environmental conditions that prevail are akin to aridity, and are therefore not different from those ascribed to agro-ecological regions IV and $\mathrm{V}$.

In Zimbabwean arid environments, climate change could aggravate droughts because of the enormous challenges that it generates for agricultural and water resources planners and managers, a situation that could be compounded by dearth of information about whether the current problems of water scarcity in the country are the result of natural climate variability, or enhanced greenhouse effects, or simply poor water resources management practices (Mazvimavi 2008). Recent debates on rainfall variability have revealed serious disagreements on this subject. In some scholarly circles it has been concluded that rainfall in Zimbabwe is progressively declining due to global warming (Makarau 1995; Unganai 1996; Mason \& Jury 1997; Chamaille-Jammes et al. 2007; Thierfelder \& Wall 2010), suggesting that the increasing frequency of drought is the outcome of climate change. To the contrary, research by Mazvimavi (1989) did not reveal any discernible trends, while Nicholson (2000) reported decadal variations of rainfall during the 1950-1989 period as a recurrence of conditions that have been previously experienced, rather than a new phenomenon. Without conclusive evidence on the link between climate change and patterns and trends of drought occurrence in Zimbabwe it remains necessary to undertake a geospatial and temporal analysis of rainfall variability so as to plan better for this hazard. This is important because in Zimbabwe, as is the case with the rest of Africa, rainfall variability poses stress on virtually all sectors of the economic activity and social well-being. Furthermore, since the national economy is largely agro-based and principally rainfed, drought poses serious threats to food security and livelihood sustainability. In Africa as a whole, chronic overuse and water stress is high for $25 \%$ of the population, while $13 \%$ of the population experiences drought related problems, though modest increases in water use could reduce constraints on economic development, pollution, and challenges to human health (Vörösmarty et al. 2005). Proper management of droughts requires knowledge of the expected frequency of specific low magnitude precipitation totals for a variety of durations (Núñez et al. 2011).

While some research has been done on drought quantification and a large number of drought 


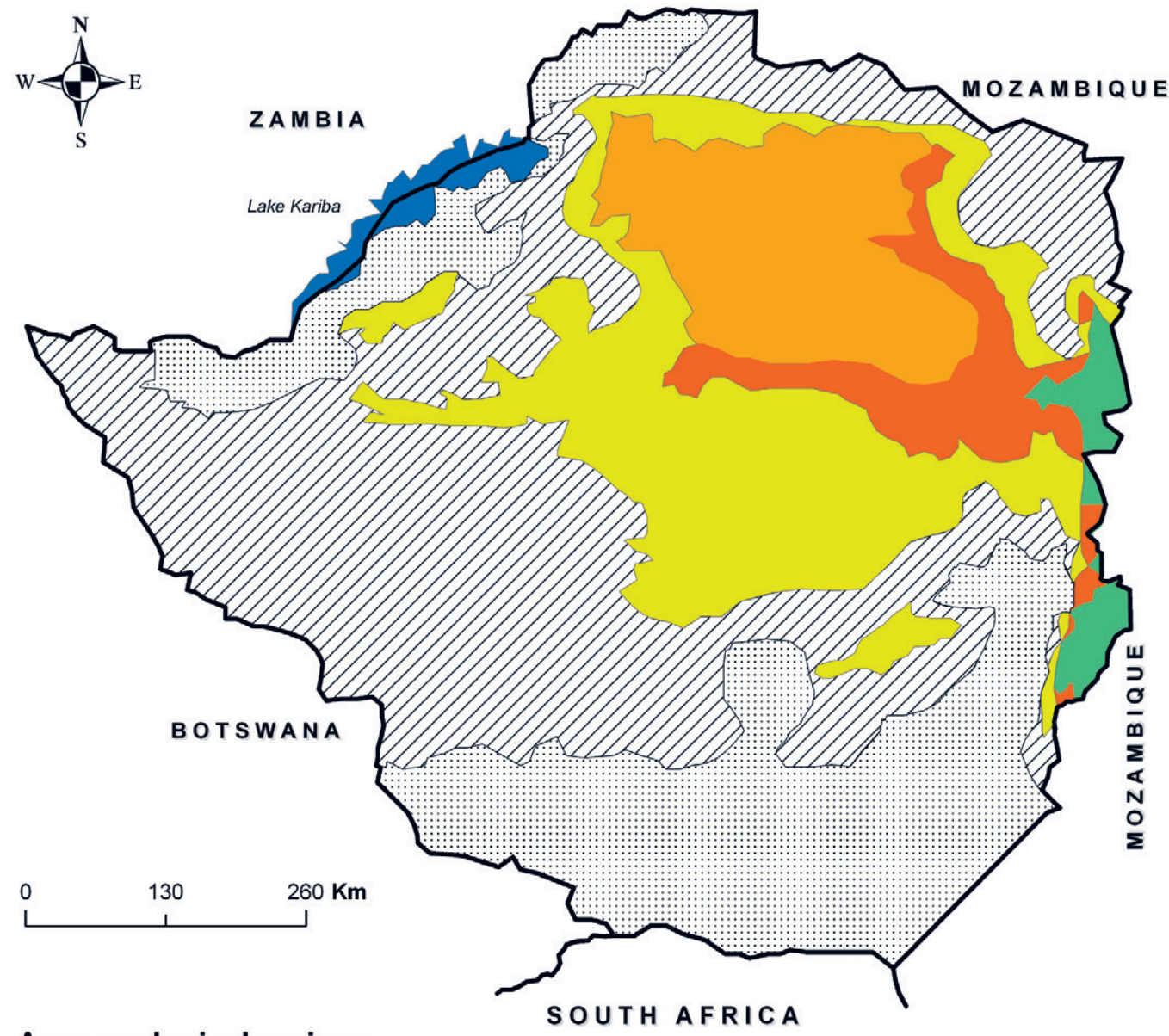

\section{Agro-ecological regions}

SOUTH AFRICA

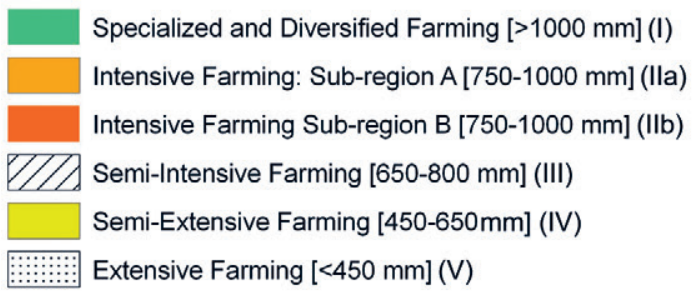

Figure 1. Agro-ecological regions of Zimbabwe (adapted from OCHA 2009).

analyses are found in literature (Kim \& Valdes 2002), including drought indices (Heim 2002), in Zimbabwe attention still needs to be given to geospatial and temporal characteristics of drought years and aridity. Gaps still exist in what is known about geospatial and temporal patterns of drought occurrence. This is partly because the msechanisms underlying these patterns are not yet fully understood, while disagreements on the mechanisms that are responsible for these patterns are copious in existing literature (Manatsa et al. 2011).
Consequently, research is needed to understand the spatio-temporal complexity of droughts under climate change due to the spatio-temporal variable nature of precipitation (Ashok et al. 2011).

In southern Africa, research is made even more necessary by the fact that drought events are still largely monitored by a 'percent of normal' index. Although this is considered as effective in analyzing a single region or a single season, it falls short of adequately representing the earlier identified important drought dimensions (Manatsa et al. 
2010). Besides, most of the research on drought has tended to focus on the rain season and the immediate period preceding it. In some research it has been argued that the characteristics of the growing season are influenced by how rainfall is distributed rather than by the total amount of rainfall received (Twomlow et al. 2006). A related argument that has been advanced is that there is no correlation between total rainfall received and crop yields, and consequently the years with highest rainfall records do not necessarily correspond with the years in which the highest crop yields are recorded (van Oosterhout 1996), though some research has established that in some semi-arid areas of Zimbabwe high spatial and temporal rainfall variability during the growing season increases the risk of mid-season dry spells (Mupangwa 2008; Mupangwa et al. 2011). Some evidence from the research cited above has shown that the 'goodness' of rainfall distribution is determined by the probability of dry spells (Stroosnijder 2007; Nyakudya \& Stroosnijder 2011). Conclusions drawn from this research seem to demonstrate that poor distribution of rainfall over time constitutes a more common cause of crop failure than absolute water scarcity due to low cumulative annual rainfall (Barron 2004; Muhammad \& Reason 2004; Barron \& Kwacha 2005).

While these arguments imply that the productivity of a cropping season is a function of how rainfall is distributed in a cropping season rather than the total amount of rainfall received, in reality all the rains that fall during any time of the year play an important role in agriculture, either directly by augmenting water supplies for livestock on which most small scale farmers depend for draught power, or indirectly by replenishing soil moisture reserves. Antecedent soil moisture is vital for crop farming and pasture regeneration. Research in conservation agriculture in Zambia and Zimbabwe has demonstrated that water-efficient cropping systems are partly based on soil moisture status (Thierfelder \& Wall 2010). Unlike previous studies on drought, therefore, this study is unique because it puts into consideration the total amount of rainfall received per year as opposed to the rainfall that is received during the cropping season only.

Whereas the rainfall thresholds that were used to delimit Zimbabwe's agro-ecological regions are important for understanding the long-term average annual rainfall distribution for the whole country, the interpolation of the threshold values across the country could be improved through geospatial and temporal analysis. The purpose of this research study is therefore to determine the geospatial and temporal variability of the arid zones in Zimbabwe, using archival rainfall data for the period between 1940 and 1999 .

\section{Materials and methods}

The methodology of this study was two-pronged, embracing temporal (time series) analysis and geospatial analysis, as detailed below. Archival data on Zimbabwe's average annual rainfall was statistically analyzed for trends. To achieve this objective time series analysis of annual average rainfall data was performed for 67 meteorological stations for the period between 1940 and 1999. The first step involved the classification of stations into clusters according to the average annual rainfall they received between 1940 and 1999. This clustering was achieved through a Getis Ord hot spots analysis (HSA). ESRI ArcGIS 9.3 was used to perform the analysis. The database files that were used in the HSA were created in Microsoft Excel. Besides providing a visual impact on spatial distribution, HSA unveils the general geographical patterns that are dominant in a region, which would not have resulted by chance. This is important, considering the need for understanding patterns of drought years in an environment where the food security and livelihoods of the majority of people directly depend on rainfed agriculture, making water resources planning a critical element of any successful agricultural year. The Getis Ord (Gi) HSA identifies clusters of higher and lower magnitude than would be randomly found and its statistical output is in the form of a $Z$ score, referred to as a GiZ score. For each cluster, the average annual rainfall was calculated by dividing the product of sixty (for the sixty years being considered in this study) and the number of stations in that cluster into the sum of the total annual rainfall values for the stations in the cluster. The formula that was used was:

$$
\bar{x}=\sum x(60 N)^{-1}
$$

where $\bar{x}$ - cluster's average annual rainfall, $\sum x$ - total annual rainfall received by the stations in a given cluster over a period of 60 years, and $\mathrm{N}$ - the number of stations in the cluster. 
Time series graphs were plotted for the average annual rainfall received by the stations in each cluster. For each station the drought years were considered to be the number of years in which the total annual rainfall received by the station was less than the cluster's average annual rainfall. Thus a station was considered to have experienced a drought year when its total annual rainfall was below normal, i.e. the cluster's average annual rainfall. The total number of drought years was determined for each of the six decades included in the study.

As part of the geospatial analysis of drought frequency, GiZ scores for the number of drought years experienced at each station for each decade were computed and spatially interpolated. The GiZ scores were kriged and for each decade isarithms for the GiZ scores were plotted on a base map. This provided an alternative mechanism for comparing the geospatial and temporal characteristics of drought years without the need to delineate homogeneous precipitation regions. The delineation of homogeneous precipitation regions (regionalization) is normally considered as necessary for investigating frequency and spatial distribution of meteorological droughts (Satyanarayana \& Srinivas 2011). Satyanarayana and Srinivas (2011), however, argue that the conventional methods of regionalization which use statistics of precipitation as attributes to establish homogeneous regions have the limitation that they cannot be used to form regions in ungauged areas, and they may not be useful to form meaningful regions in areas having sparse rain gauge density.

Areas of high drought frequency were characterized by GiZ scores that exceeded 1.96. These are the areas that were termed arid zones. From a statistical viewpoint, the 1.96 score is the approximate value of the 97.5 percentile point of the distribution. The GiZ scores were kriged and isarithms joining areas of equal GiZ score values were generated. The next step involved testing if inter-decadal variations in aridity were statistically significant. Prior to the significance testing the Shapiro-Wilk test was performed to check the normality of the data. This was an important step in the selection of appropriate significance tests. Data for two of four of the decades revealed absence of normality. Consequently, the Kruskal-Wallis test was employed to perform the significance testing. The test was performed at 95\% confidence level. The Statistical Package for the Social Sciences was used to perform the test. Statistically significant differences between GiZ scores were considered to be an indicator of changing intensity of aridity and therefore an indicator of climate change. The $\mathrm{H}_{0}$ tested was: "There is no difference between the GiZ scores for the drought years experienced by different clusters during the six decades".

\section{Results}

\section{Temporal variability of average annual rainfall and drought years in Zimbabwe}

Average annual rainfall in Zimbabwe is extremely variable. Figure 2 shows the clusters that resulted from the HSA of rainfall data, while Table 1 presents the general rainfall characteristics of each cluster. However, with the exception of the Central cluster, there has been a general decline in the average annual rainfall received throughout Zimbabwe, as shown by the regression equations for trend lines in Figure 3 (b, c, d and e).

In general (as shown in Table 1) clusters that registered the highest $\mathrm{GiZ}$ scores are the once whose average annual rainfall values are the highest. In each cluster the average number of drought years has been fluctuating. However, these averages may not reveal much since there are some stations in each cluster which have experienced higher values, thus demonstrating that trends of aridity vary geographically. Using our definition of drought year, it can be noted that the eastern region, which receives the highest average annual rainfall in the country, is highly prone to drought. Some areas that occur in this region have experienced arid conditions (with GiZ scores exceeding 1.96) in all decades except the 1960-1969 and 1980-1989 periods.

With the exception of the Western cluster, which receives the lowest amounts of rainfall in the country the most widespread droughts in Zimbabwe were experienced during the 1992-1993 period. However, the most widespread drought took place during the 1990-1991 period when 98\% of the stations in Zimbabwe received less than $650 \mathrm{~mm}$ of rainfall. Even though the total number of drought years that were experienced fluctuated in all clusters, the more northerly clusters, namely the Eastern, Southeast-Northwest and Northeastern clusters, have experienced an increase in the average number of drought years between 1970 and 1999. This trend can be explained by prevailing rainfall trends (Fig. 3), which show a general 


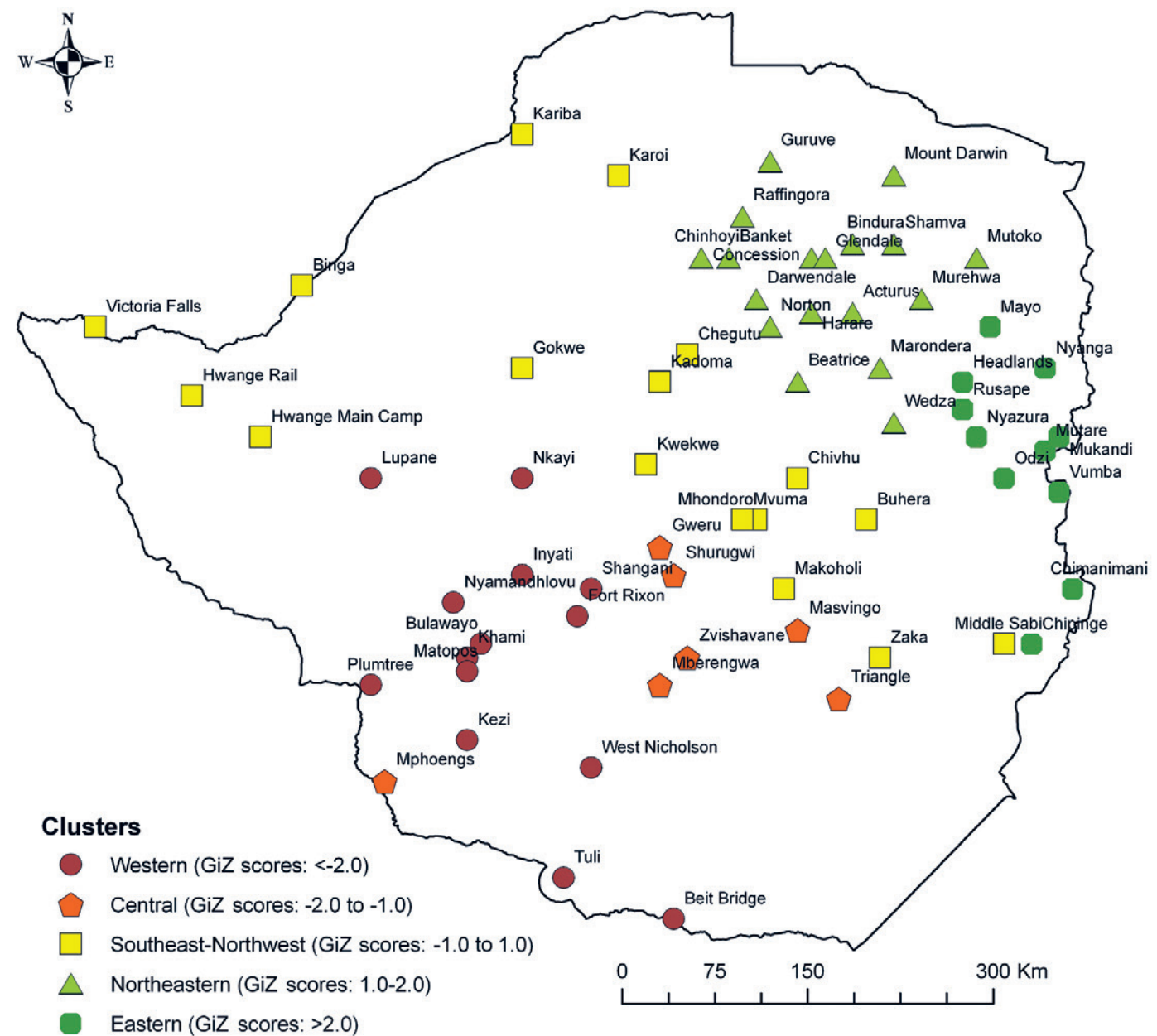

Figure 2. Rainfall clusters in Zimbabwe.

Table 1. Characteristics of the rainfall clusters between 1940 and 1999.

\begin{tabular}{|c|c|c|c|c|c|c|c|c|c|}
\hline \multirow{2}{*}{ Cluster name } & \multirow{2}{*}{$\begin{array}{c}\text { Number } \\
\text { of stations } \\
\text { in cluster } \\
(\mathrm{N})\end{array}$} & \multirow{2}{*}{$\sum x$} & \multirow{2}{*}{$\begin{array}{c}\text { Average } \\
\text { annual } \\
\text { rainfall } \\
\left(\sum \times(60 N)^{-1}\right)\end{array}$} & \multicolumn{6}{|c|}{ Average number of drought years per cluster } \\
\hline & & & & 1940-49 & $1950-59$ & $1960-69$ & $1970-79$ & 1980-89 & 1990-99 \\
\hline Eastern & 11 & 735768.0 & 1114.8 & 7 & 6 & 7 & 6 & 7 & 7 \\
\hline Northeastern & 18 & 893376.0 & 827.2 & 5 & 4 & 6 & 5 & 5 & 6 \\
\hline Southeast-Northwest & 17 & 597516.0 & 585.8 & 4 & 2 & 4 & 2 & 4 & 4 \\
\hline Central & 6 & 240192.0 & 667.2 & 7 & 5 & 7 & 5 & 7 & 6 \\
\hline Western & 14 & 461664.0 & 549.6 & 6 & 4 & 7 & 4 & 7 & 6 \\
\hline
\end{tabular}

decline in rainfall in all clusters during this period, though the Central cluster is an exception.

It can therefore be concluded that drought patterns of drought years in Zimbabwe are not only oscillatory but are also linked to a gradual longterm decline of rainfall (Fig. 3). However, the actual geospatial patterns patterns of drought year frequency could only be revealed through a Getis Ord hot spots analysis (HSA) as discussed in the next section of this paper. 


\section{Spatial variability of drought years in Zimbabwe}

As shown in Figure 4, results from the Getis Ord (Gi) HSA indicate that drought year occurrence is a highly variable phenomenon in Zimbabwe, ranging from the Western cluster (Fig. 2), where it is almost a permanent feature in a pronounced arid zone (with GiZ scores exceeding 1.96 in five consecutive decades) to the Eastern cluster where drought years are an intermittent phenomenon. It is interesting to note that aridity is a well-established and almost permanent feature in the southwestern part of the country, which receives the least average annual rainfall in the country, and also a common feature of eastern Zimbabwe, which constitutes the wettest part of the country (Fig. 4). In the western part of the country, all the areas whose average decadal GiZ scores are greater than 1.96 are spatially linked to this region. $A$ unique phenomenon that developed in eastern Zimbabwe during the 1990-1999 decade is the emergence of disjointed pockets of aridity spreading over the northern flanks of the Eastern cluster and the southeastern margins of the Northeastern cluster (Fig. 4).

This area is part of agro-ecological region III (Fig. 1), which is usually considered as a relatively moist area. The emergence of disjointed pockets of aridity during the 1990-1999 decade, suggests that there are some localized confounding conditions that had an influence on rainfall distribution during this period. Having analyzed the general patterns of drought years in the country it remained necessary to examine the extent to which the differences in patterns were statistically significant.

Table 2 shows the results of the Kruskal-Wallis test of the GiZ scores for the drought years that were recorded in all rainfall clusters between 1940 and 1999.

As shown in Table 2, in all cases drought occurrence was differed significantly between clusters, showing that different clusters have experienced different patterns of aridity.

\section{Discussion}

This study has revealed both sporadic oscillatory patterns and trends of drought year occurrence. The results from the study indicate that in Zimbabwe drought occurrence is highly variable, both geospatially and temporarily. The results also show that there is a well-established and persistent core arid zone which is confined to the southwestern part of the country. The Kruskal-Wallis test revealed statistically significant differences between the GiZ scores for the number of drought years recorded in the five clusters that occur in the country. What is interesting is that all areas whose average GiZ scores exceed 1.96 in all the six decades are located either in the southwestern and northeastern flanks of the country. Unlike the southwestern arid zone which is continuous and persistent the northeastern zone is intermittent, and in some cases 'leap frogging', as has been the case during the 1990-99 decade.

The southwestern arid zone nestles in the same region where anticyclonic conditions persist in summer. It is already an established fact that anticyclonic conditions prevailing in the region are characterized by rainfall suppression due to subsidence (Unganai \& Manson 2002). Aridity results from the presence of dry, descending air and occurs mostly in places where anticyclonic conditions are persistent (Some'e et al. 2012). However, it could not be established within the scope of this study whether the complex, but cyclic patterns of drought years occurrence has any synergy with patterns of the suggested anticyclonic conditions. What is evident though are decadal variations in average annual rainfall, confirming findings from earlier research, which have shown that rainfall is highly variable on all timescales (Mason \& Jury 1997; Tyson \& Preston-Whyte 2000;

Table 2. Results from the Krusak-Wallis test for the GiZ scores for the number of drought years recorded in different clusters between 1940 and 1999.

\begin{tabular}{|l|c|c|c|c|c|c|}
\hline & $\begin{array}{c}\text { GiZ scores for } \\
1940-1949\end{array}$ & $\begin{array}{c}\text { GiZ scores for } \\
1950-1959\end{array}$ & $\begin{array}{c}\text { GiZ scores for } \\
1960-1969\end{array}$ & $\begin{array}{c}\text { GiZ scores for } \\
1970-1979\end{array}$ & $\begin{array}{c}\text { GiZ scores for } \\
1980-1989\end{array}$ & $\begin{array}{c}\text { GiZ scores for } \\
1990-1999\end{array}$ \\
\hline Chi-Square & 20.576 & 26.132 & 19.115 & 36.809 & 29.692 & 30.697 \\
df & 4.000 & 4.000 & 4.000 & 4.000 & 4.000 & 4.000 \\
Asymp. Sig. & 0.000 & 0.000 & 0.001 & 0.000 & 0.000 & 0.000 \\
\hline
\end{tabular}


320

Geoffrey Mukwada - Desmond Manatsa

a) Eastern cluster

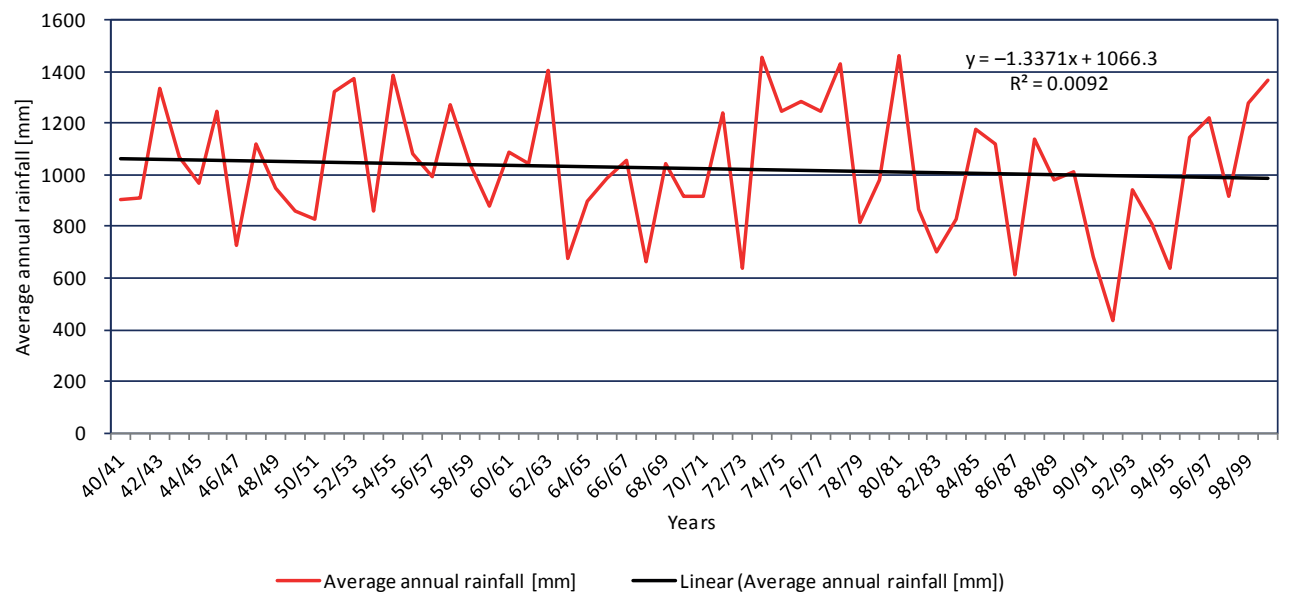

b) Central cluster

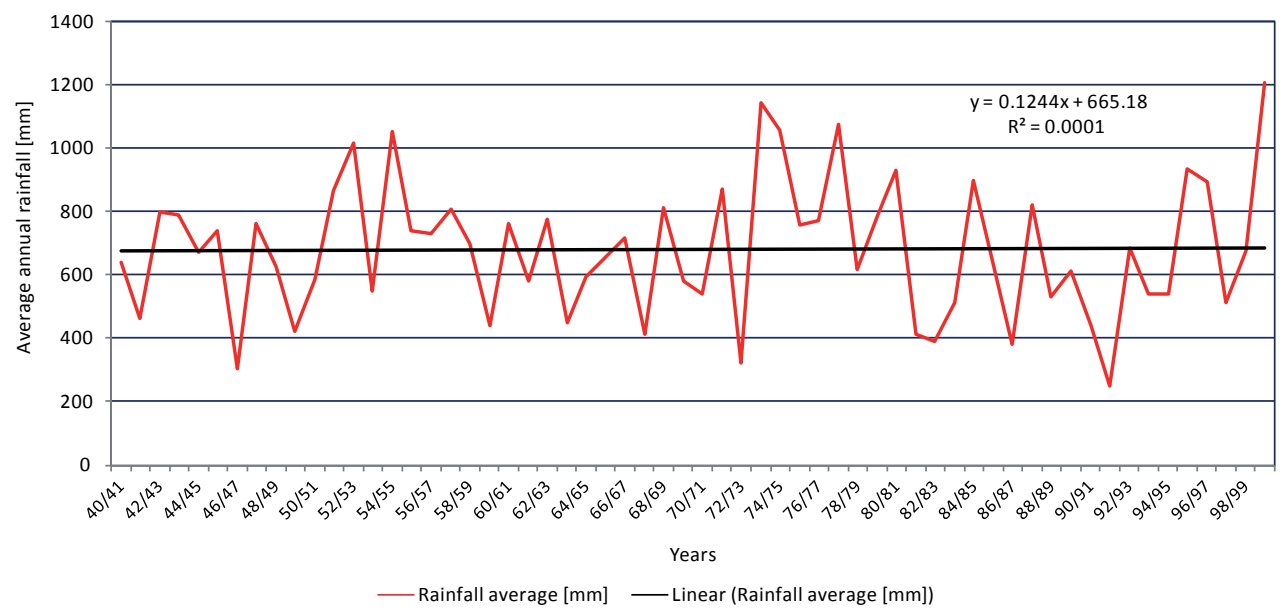

c) Northeastern cluster

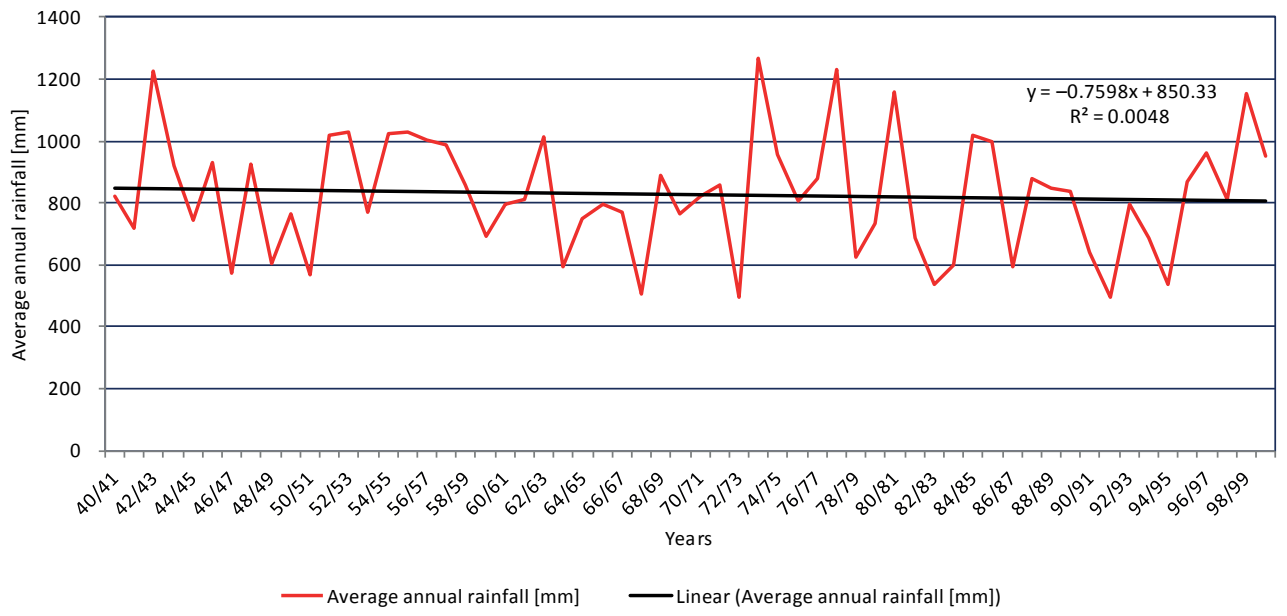

Geographic Polonica 2013, 86, 4, pp. 313-326 
d) Southeast-northest cluster

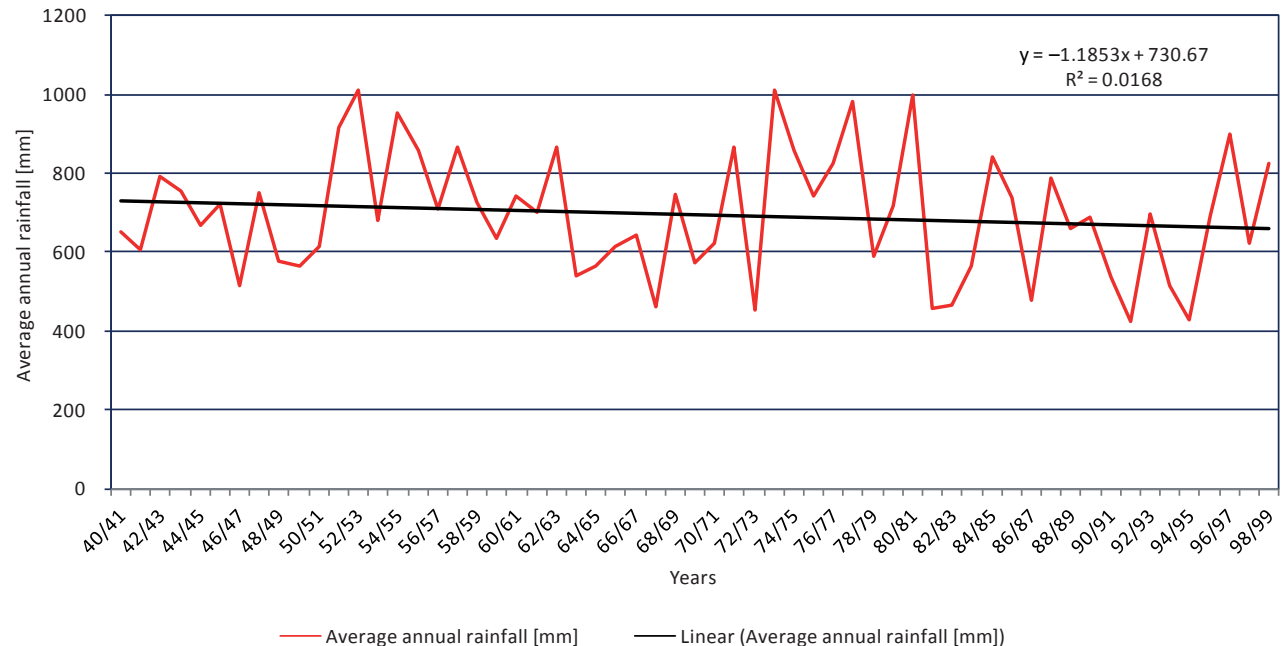

e) Western cluster

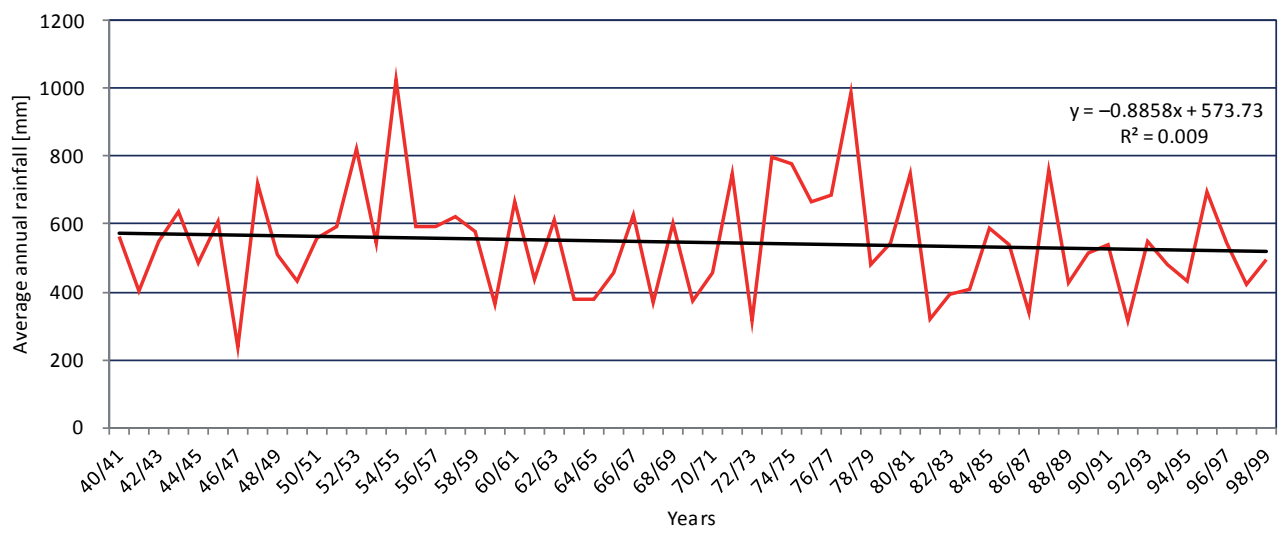

— Average annual rainfall [mm] _Linear (Average annual rainfall [mm])

Figure 3. Temporal variability of rainfall in different regions in Zimbabwe (a-e).

Reason \& Rouault 2002). Nevertheless, the cyclic variations are embedded in trends of progressive desiccation, as shown in Figure 3. This reality is not necessarily incontrovertible. First, it should be noted that a probabilistic approach was followed in this study. Núñez et al. (2011) noted that though probabilistic approaches have often been used to estimate the average recurrence period of a given drought event, these approaches are not necessarily always accurate. Second, this study has revealed an increasing trend in the frequency of drought years, a phenomenon that has been previously disputed. For example, using robust statistical analysis Mazvimavi $(1989,2008)$ disputed the notion of trends depicting progressive desiccation. One possible explanation for differences in the findings of this research and those from previous research may simply be the differences in research approaches and size of sample used. For instance, whereas Mazvimavi's (2008) study focused on rainfall records from 40 stations for the period between 1892 and 2000 the current study focused on records from 67 stations for the period between 1940 and 1999. However, the trend lines in Figure 3 (a, c, d, and e) and the patterns of isarithms in Figure 4 clearly imply progressive desiccation or increasing frequency of drought in most parts of the country. However, the differences in research results indicate that the spatio-temporal occurrence of drought in an 


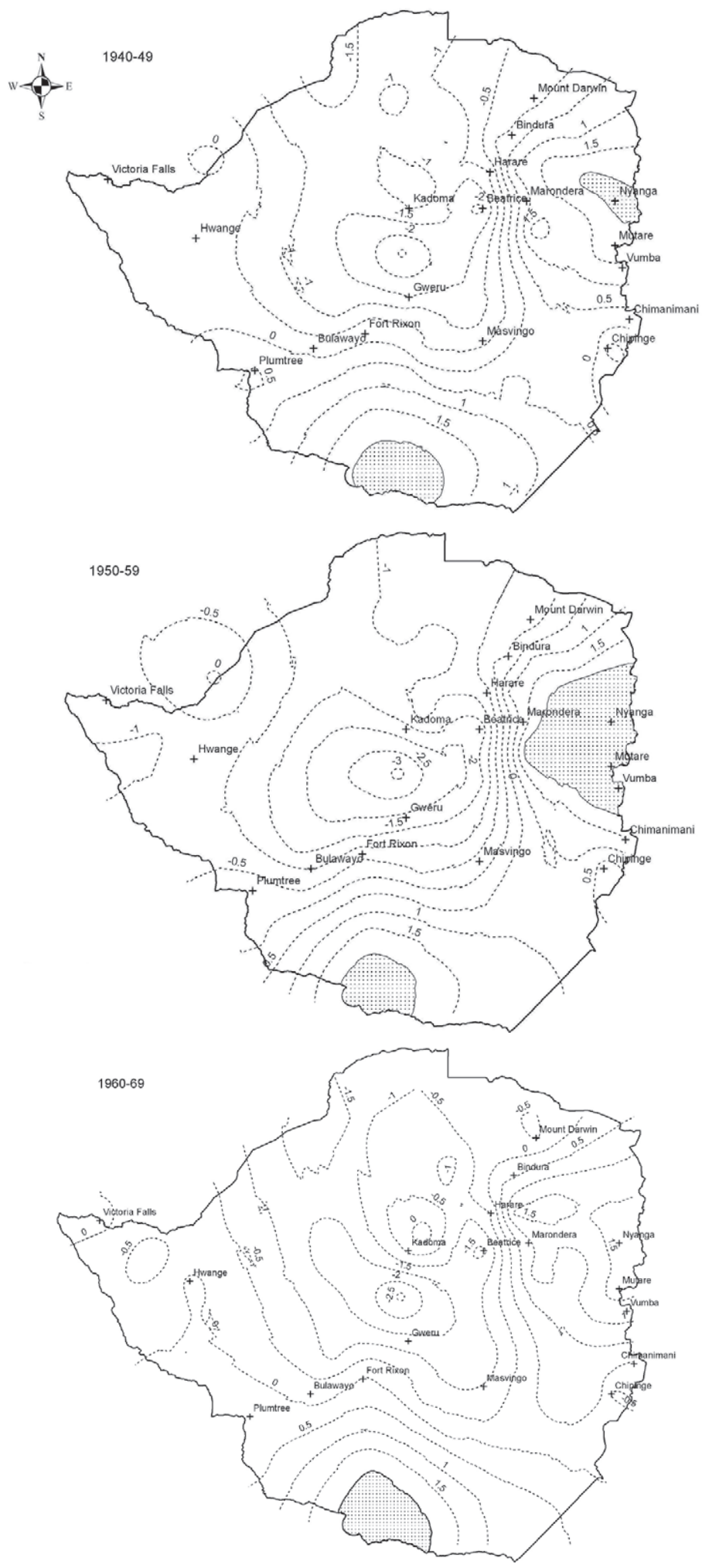




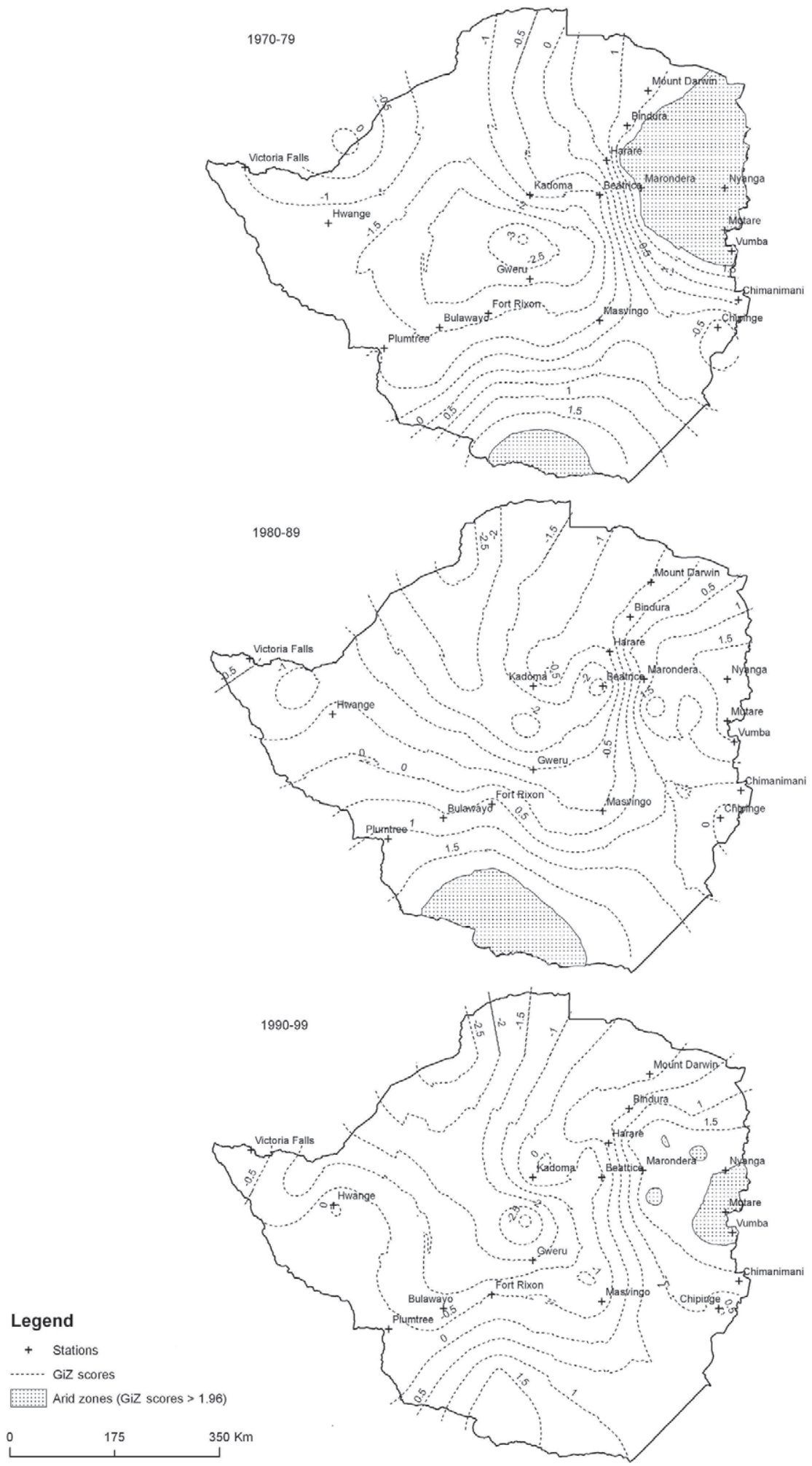

Figure 4. Distribution of arid zones in Zimbabwe. 
environment characterized by climate change is a complex phenomenon (Mishra \& Singh 2011).

While the notion of intensification of climate change or progressive desiccation in southern Africa is still being debated, the variability of aridity in southwestern and northeastern parts of Zimbabwe cannot be questioned. The oscillatory forays that the arid zones are making along the fringes of these drought prone areas have serious implications on rural livelihoods, especially in the highly populated communal areas (agro-ecological regions III and IV) where survival depends on rainfed agriculture. For the Zimbabwean agricultural sector, and the national economy as a whole, the implications of these findings are important for developing relevant mitigatory or intervention strategies. Different strategies should be adopted for coping with drought in different geospatial regions. As noted by Wilhite (2003), moving from crisis to risk management will require the adoption of a new paradigm for land managers, governments, international and regional development organizations, and non-governmental organizations. In the relatively arid southwestern parts of the country (where the arid zone is located), rural livelihood interventions by government, water resources planners and managers, donors and NGOs may need to shift from agriculture to off-farm livelihood strategies, since water scarcity is worsening. This will reduce chronic overuse of water in the region. Such a strategy calls for a paradigm shift in land use planning. In this region, the land based economic activities that should be developed must be those that are less dependent on rainfed agriculture, for instance, game farming and tourism. Where farming has to be practiced it should either be based on activities that require low water inputs, for instance the cultivation of drought resistant crops such as small grains, or those activities based on abstraction of water from perennial rivers and aquifers, e.g. irrigation farming or extensive farming systems such as livestock ranching. Water conserving and efficient irrigation technologies, including those that promote soil water conservation, must be developed. Due to their drought proneness, the arid regions, which typically fall under agro-ecological regions III, IV and $V$, (where annual rainfall is usually variable) have traditionally been deemed suitable for livestock farming rather than cultivation (Manjengwa et al. 2012). The drought resistant food crops that would be most suitable for these regions which are currently grown in Zimbabwe include cowpeas (Vigna unguiculata), finger millet (Eleusine coracana) and sorghum (Sorghum bicolor). Reliance on these less sensitive crops will enable farmers to adopt more water-efficient cropping systems, including conservation agriculture, to mitigate the effects of climate change (Thierfelder \& Wall 2010). Other adaptation strategies could involve changes in crop varieties and planting dates (Lobell et al. 2008; Gwimbi 2009).

Drought resistant livestock that are commonly raised in southwestern parts of Zimbabwe include donkeys and small ruminants, especially goats. Farmers in the previously more moist areas that are now being swathed by the arid zone should be encouraged to raise these animals as a way of mitigating drought. In addition, in the light of the increasing drought frequency, farmers in wetter regions abutting the arid zones and the drought prone areas should be accorded better government support to enable them to adopt strategies that allow them to cope better with drought, including the development of cultivars and livestock breeds that enhance yields in arid environments. Such support could include training and environmental awareness campaigns. Considering the inconclusive evidence from recent research on rainfall trends and the notion of progressive desiccation or climate change, it becomes even more necessary to introduce government funded irrigation infrastructure in areas that were previously considered as moist, unlike in the past when government funded irrigation projects were confined to the drier parts of the country. In the relatively more moist regions government could provide subsidies to commercial farmers to enable them to construct dams or sink boreholes so as to enhance irrigation infrastructure and make agriculture based livelihoods more sustainable.

\section{Conclusions}

The purpose of this research study was to determine the geospatial and temporal characteristics of aridity in Zimbabwe, between 1940 and 1999. The study involved time series and geospatial analyses. Two main conclusions emerge from the foregoing discussion. First, there has been an increase in the number of drought years, signifying that Zimbabwe could be under the influence of climate change. Second, there are well-established arid zones, one in the southwest and another in 
the northeast, whose fronts are progressively changing. In the southwest aridity is almost permanent, while in the northeast it is occurring in an oscillatory manner. Statistically significant differences between GiZ scores for the number of drought years were indicative of changing intensity of aridity and a possible indicator of climate change. Finally, it can also be concluded that rural

\section{References}

Ashok K., Mishra A.K., Singh V.P., 2011. Drought modeling - a review. Journal of Hydrology, vol. 403, iss. 1-2, pp. 157-175.

BARRON J., 2004. Dry spell mitigation to upgrade semi-arid rainfed agriculture: Water harvesting and soil nutrient management for smallholder maize cultivation in Machakos, Kenya. Stockholm: Institutionen för systemekologi, 38 pp. [PhD Thesis].

BARRON J., KWACHA G., 2005. Run-off water harvesting for dry spell mitigation in maize (Zea mays L.): Results from on-farm research in semi-arid Kenya. Agricultural Water Management, vol. 74, no. 1, pp. 1-21.

Chamaille-Jammes S., Fritz H., Murindagomo F., 2007. Detecting climate changes of concern in highly variable environments: Quantile regressions reveal that droughts worsen in Hwange National Park, Zimbabwe. Journal of Arid Environments, vol. 71, no. 3, pp. 321-326.

GWIMBI P., 2009. Cotton farmers' vulnerability to climate change in Gokwe District (Zimbabwe): impact and influencing factors. Journal of Disaster Risk Studies, vol. 2, no. 2, pp. 81-92.

Hallack-Alegria M., Watkins D.W., 2007. Annual and warm season drought intensity-duration-frequency analysis for Sonora, Mexico. Journal of Climate, vol. 20, no. 9, pp. 1897-1909.

HEIM R.R., 2002. A review of twentieth-century drought indices used in the United States. Bulletin of the American Meteorological Society, vol. 83, no. 8, pp. 1149-1165.

KIM T.W., VAldeS J.B., 2002. Frequency and spatial characteristics of droughts in the Conchos River basin, Mexico. Water International, vol. 27, no. 3, pp. $420-430$.

Lobell D.B., Burke M.B., Tebaldi C., Mastrandrea M.D., Falcon W.P., Naylor R.L., 2008. Prioritizing climate change adaptation needs for food security in 2030. Science, vol. 319, no. 5863, pp. 607-610.

MAKARAU A., 1995. Intra-seasonal oscillatory models of the southern Africa summer circulation. Cape Town: livelihood strategies in Zimbabwe need to be revised in the light of both oscillatory patterns of drought years and inconclusive evidence of trends of progressive aridity.

Editors' note:

Unless otherwise stated, the sources of tables and figures are the author(s), on the basis of their own research.

University of Cape Town. Department of Oceanography [PhD Thesis].

Makaudze E.M., MiRanda M.J., 2010. Catastrophic drought insurance based on the remotely sensed normalised difference vegetation index for smallholder farmers in Zimbabwe. Agricultural Economics Research, Policy and Practice in Southern Africa, vol. 49, no. 4, pp. 418-432.

Manatsa D., Mukwada G., Siziba E., Chinyanganya T., 2010. Analysis of multidimensional aspects of agricultural droughts in Zimbabwe using the Standardized Precipitation Index (SPI). Theoretical and Applied Climatology, vol. 102, no. 3-4, pp. 287-305.

Manatsa D., Nyakudya I.W., Mukwada G., Matsikwa H., 2011. Maize yield forecasting for Zimbabwe farming sectors using satellite rainfall estimates. Natural Hazards, vol. 59, no. 1, pp. 447-463.

Manatsa D., Unganal L., Gadziral C., Behera S.K., 2012. An innovative tailored seasonal rainfall forecasting production in Zimbabwe. Natural Hazards, vol. 64, no. 2, pp. 1187-1207.

Manjengwa J., Kasirye I., Matema C., 2012. Understanding poverty in Zimbabwe: A sample survey in 16 Districts. Paper prepared for presentation at the Centre for the Study of African Economies Conference 2012 "Economic Development in Africa", Oxford, United Kingdom, March 18-20, 2012, 19 pp.

MAsOn S.J., JuRY M., 1997. Climatic variability and change over Southern Africa: A reflection on underlying processes. Progress in Physical Geography, vol. 21, no. 1, pp. 23-50.

MazVIMAVI D., 1989. Analysis of annual rainfall in Zimbabwe for trends and periodicities, 1891-1988. Geographical Journal of Zimbabwe, vol. 20, pp. 42-52.

MaZVIMAVI D., 2008. Investigating possible changes of extreme annual rainfall in Zimbabwe. Hydrology and Earth System Sciences Discussions, vol. 5, no. 4, pp. 1765-1785.

Muhammad T.U., Reason C.J.C., 2004. Dry spell frequencies and their variability over Southern Africa. Climate Research, vol. 26, no. 3, pp. 199-211. 
MupANGWA W., 2008. Water and nitrogen management for risk mitigation in semiarid cropping systems. Phuthaditjhaba: University of Free State. Department of Soil, Crop and Climate Sciences [unpublished PhD thesis].

Mupangwa W., Walker S., Twomlow S., 2011. Start, end and dry spells of the growing season in semi-arid southern Zimbabwe. Journal of Arid Environments, vol. 75, no. 11, pp. 1097-1104.

Nicholson S.E., 2000. The nature of rainfall variability over Africa on time scales of decades to millennia. Global and Planetary Change, vol. 26, iss. 1-3, pp. 137-158.

Núñez J.H., Verbist K., Wallis J.R., Schaefer M.G., Morales L., Cornelis W.M., 2011. Regional frequency analysis for mapping drought events in north-central Chile. Journal of Hydrology, vol. 405, iss. 3-4, pp. 352-366.

Nyakudya I.W., Stroosnijder L., 2011. Water management options based on rainfall analysis for rainfed maize (Zea mays L.) production in Rushinga district, Zimbabwe. Agricultural Water Management, vol. 98, iss. 10, pp. 1649-1659.

OCHA, 2009. Zimbabwe: Agro-ecological zones map (as of 05 Oct 2009). http://reliefweb. int/map/zimbabwe/zimbabwe-agro-ecological-zones-map-05-oct-2009 [8 January 2013].

Reason C.J.C., Rouault M., 2002. ENSO like decadal variability and southern African rainfall. Geophysical Research Letters, vol. 29, no. 13, pp. 1-16.

Satyanarayana P., Srinivas V.V., 2011. Regionalization of precipitation in data sparse areas using large scale atmospheric variables - A fuzzy clustering approach. Journal of Hydrology, vol. 405, iss. 3-4, pp. 462-473.

Somée B.S., Ezani A., TABARI H., 2012. Spatiotemporal trends of aridity index in arid and semi-arid regions of Iran. Theoretical Applied Climatology, vol. 111, no. $1-2$, pp. 149-160.

Stroosnijder L., 2007. Rainfall and land degradation. [in:] M.V.K. Sivakumar, N. Ndiang'ui (eds.), Climate and land degradation, Berlin-New York: Springer, pp. 167-195.

Thierfelder C., Wall P.C., 2010. Investigating conservation agriculture (CA) systems in Zambia and Zimbabwe to mitigate future effects of climate change. Journal of Crop Improvement, vol. 24, no. 2, pp. 113-121.

Twomlow S.J., Steyn J.T, du Preez C.C., 2006. Dryland farming in southern Africa. [in:] G.A. Petersen, W.P. Unger, W.A. Payne (eds.), Dryland agriculture. Agronomy, no. 23, Madison (Wis.): American Society of Agronomy, pp. 769-836.

Tyson P., Preston-Whyte R., 2000. The weather and climate of Southern Africa. Cape Town: Oxford University Press, 396 pp.

UnGANAI L., 1996. Historic and future climatic change in Zimbabwe. Climate Research, vol. 6, no. 2, pp. 137-145.

UnganaI L.S., Manson S.J., 2002. Long-range predictability of Zimbabwe summer rainfall. International Journal of Climatology, vol. 22, no. 9, pp. 1091-1103.

Van Oosterhout S.A.M., 1996. Coping strategies of smallholder farmers with adverse weather conditions regarding seed deployment of small grain crops during 1994/1995 cropping season in Zimbabwe. Harare: SADC/GTZ, $376 \mathrm{pp}$.

Vincent V., Thomas R.G., Staples R.R., 1960. An agricultural survey of Southern Rhodesia: Part I: Agro-ecological survey. Salisbury: Government Printer, 147 pp.

Vörösmarty C.J., Douglas E.M., Green P.A., RevenGA C., 2005. Geospatial indicators of emerging water stress: an application to Africa. AMBIO: A Journal of Human Environment, vol. 34, no. 3, pp. 230-236.

Wilhite D.A., 2002. Combating drought through preparedness. Natural Resources Forum, vol. 26, no. 3, pp. 275-285. 